\title{
In vitro Antimicrobial Activity of Bangladeshi Artocarpus lakoocha Roxb Fruits
}

\author{
Srabonti Saha* \\ Department of Biochemistry and Molecular Biology, University of Chittagong, \\ Chittagong-4331, Bangladesh \\ *Corresponding author
}

A B S T R A C T

\section{Keywords}

Artocarpus

lakoocha,

Antibacterial activity, Antifungal activity, Zone of inhibition

Article Info

Accepted:

04 January 2019

Available Online:

10 February 2019
Microorganisms play a crucial role in living organisms. Some microorganisms are beneficial for us some are pathogenic. The aim of the study is to evaluate the activity of the fruits of Artocarpus lakoocha Roxb. against certain pathogenic microbial strains. Petroleum ether, chloroform and methanol extract of these fruits were used by disk diffusion method on Escherichia coli, Bacillus subtilis, Staphylococcus aureus, Salmonella typhi, Bacillus cereus, Salmonella paratyphi and two fungal strains. All the fruit extracts showed the antimicrobial activity against all the microorganisms. Among the three extracts, methanolic fruit extracts exhibited significant activity against the microorganisms and fruit extracts of petroleum ether showed the least activity against the certain microorganisms. The fruit extracts showed antibacterial activity with a zone of inhibition of 4 to $20 \mathrm{~mm}$. The methanolic fruit extract of Artocarpus lakoocha Roxb showed antibacterial activity with a zone of inhibition of 17 to $20 \mathrm{~mm}$. The study recommended that the fruits of Artocarpus lakoocha Roxb. exhibited significant antimicrobial activity.

\section{Introduction}

For a long period of time, medicinal plants are used as a rich source in traditional and sanctioned medicine (Prashant et al., 2008). As medicinal plants have a potential source of potent medicinal value, convenience to users, economic viability and low toxicity so nowadays these plants are increasing attraction for producing drugs (Calixto, 2000). It is proved that after using long term plantderived drug do not have any side effects whereas synthetic drugs have diverse side effects (Afolayan, 2003). Due to the continuous exposure of drug-resistant organisms the efficacy of current antimicrobial agents has been reduced. Although plant-based antimicrobials have enormous therapeutic potential and usefulness in the treatment of infectious diseases these antimicrobials represent a vast unexploited source of medicine (Aliero et al., 2006, Khare, 2007).

Artocarpus lakoocha (Moraceae) is a widely used medicinal plant found in Bangladesh, 
India, Thailand and Southeast Asia. All parts of this medicinal plant have diverse medicinal value (Charoenlarp et al., 2007). Generally, the fruits are eaten fresh. The fruits comprise vitamin $\mathrm{C}$ and $\beta$ carotene. Also, the fruits of Artocarpus lakoocha have antioxidative value. For the maintenance of normal health and protection from the cardiovascular disease, the antioxidative properties of fruits play an important role. The oxidative properties also combat with cancer (Jahan et al., 2011, Pandey et al., 2009).The edible fruit pulp is used as a restorative for the liver. Pickles and chutney are also made by raw fruits. The brown powder called Puag-Haad has been used as a traditional anthelmintic drug for treatment of tapeworm infection in Thailand (Salguero, 2003; Puntumchai et al., 2004). The tree bark is used to treat skin lesion and the powder form of bark is applied to cure wound (Tomar et al., 2015). The seed and bark also reduce the stomach and liver diseases. Although the ripe fruits are sweet and used as a liver tonic the unripe fruit is sour and also cause loss of appetite, blood infelicity (Piyush et al., 2014). $\beta$-amyrin acetate and lupeol acetate are present in fruits having a potential anti hyperglycemic and hypolipidemic effects that could be used as a lead compound for the production of effective in diabetes and atherosclerosis medicine (Perry, 1980). The roots of this plant showed antibacterial and cytotoxic activity (Likhitwitayawuid et al., 2005). The heartwood of $A$. lakoocha has exhibited moderate activity against herpes simplex virus and HIV (Piyush et al., 2014). The fruit pericarp of $A$. lakoocha also has antibacterial, antioxidant, anthelmintic and insecticidal activity (Sein et al., 2009). There are no reports on the antimicrobial activity of $A$. lakoocha fruits that are grown in Bangladesh.

The main objective of this study is to determine the antimicrobial potential of fruit extracts of $A$. lakoocha that are grown in
Chittagong, Bangladesh using disk diffusion assay for bacteria and fungi.

\section{Materials and Methods}

\section{Collection of plant materials}

The fresh fruits of Artocarpus lakoocha Roxb were collected from University of Chittagong during April 2018. Collected fruits were washed thoroughly in running tap water than in distilled water. After that wiped with a paper towel and weighed whole after removing the seeds. The edible portions were cut into small pieces and shade dried at room temperature $\left(25^{\circ} \mathrm{C} \pm 1\right)$ for one week in the open air. After dry the fruits were pulverized into powder form with a grinder. Then the powder was stored in airtight closed bottles and kept in a refrigerator at $4^{\circ} \mathrm{C}$ before used for analysis.

\section{Microorganisms}

Reference bacteria and fungi strains were executed from Biochemistry and Molecular Biology Department, University of Chittagong, and they included Escherichia coli, Bacillus subtilis, Staphylococcus aureus, Salmonella typhi, Bacillus cereus, Salmonella paratyphi and Candida albicans, Candida krusei.

\section{Extract preparation}

$10 \mathrm{~g}$ of air-dried powder was added to $100 \mathrm{ml}$ of petroleum ether, chloroform and methanol (Sigma Chemicals Co., St. Louis, MO, USA) separately in a conical flask, plugged with cotton wool and then kept for 7 days at room temperature with occasional stirring. The supernatant was collected by filtering with Whatman no1 filter paper and the solvent was slowly evaporated under reduced pressure below $50^{\circ} \mathrm{C}$ through an evaporator (RE200; Bibby Starling, Staffordshire, England). The 
concentrated extract was collected in a Petri dish and allowed to air-dry for the complete evaporation of solvents in the absence of sunlight and stored at $4^{\circ} \mathrm{C}$ in airtight bottles.

\section{Reference antibiotics}

Kanamycin and Nystatin were used as positive control for bacteria and fungi respectively.

\section{Study of antibacterial activity}

\section{Media preparation}

Standard nutrient agar (Difco) media was maintained for the growth $\left(37^{\circ} \mathrm{C}\right.$ and $\left.\mathrm{pH}\right)$ of the bacterial strains. The bacteria were subcultured overnight in nutrient agar broth and it was adjusted to get turbidity comparable to $0.5 \mathrm{McFarland}$ standard when requisite. For the maintenance of cultures test tube slants of nutrient agar medium were prepared. With the help of sterilized needles, small amount of the collected microorganisms were transferred to the test tubes. Under laboratory condition, the inoculated slants were inoculated at room temperature.

\section{Disk diffusion assay}

The antibacterial assay was performed using the paper disc diffusion method described by Navarro et al., 1998; Swain et al., 2008. Distinct concentrations of the fruit extracts $(0.075,0.10,0.20,0.40,0.60$, and $1.00 \mathrm{mg} / \mu \mathrm{l})$ were prepared with petroleum ether, chloroform and methanol. Nutrient agar was inoculated with a microbial cell suspension ( $200 \mu \mathrm{l}$ in $20 \mathrm{ml}$ of medium) and poured into sterile Petri dishes and rotated clockwise and counterclockwise for a few times to be seeded uniformly. Dried and sterilized filter paper discs $6 \mathrm{~mm}$ in diameter were treated with 20 $\mu l$ of each extract concentration and using micropipette and placed on the inoculated agar surface. Standard $6 \mathrm{~mm}$ antibiotic discs Kanamycin containing (30 $\mu \mathrm{g} / \mathrm{disc}$ Oxoid, Hampshire, England) was used as positive control was placed on the agar surface with sterile forceps. Negative controls were made using paper discs treated with $20 \mu \mathrm{l}$ of the solvents. After pre-incubation for $2 \mathrm{~h}$ in a low temperature $\left(4-6^{\circ} \mathrm{C}\right)$ and allowed to diffuse the test materials (antimicrobial) from the disc to the surrounding medium by this time. Then the plates were incubated overnight at $37^{\circ} \mathrm{C}$ for $24 \mathrm{~h}$ to allow the maximum growth of the organisms.

\section{Study of antifungal activity}

\section{Fungal strains}

The in vitro antifungal activity of the $A$. lakoocha fruits were studied against two human pathogenic fungal strains Candida albicans (C. albicans) and Candida krusei ( $C$. krusei).

\section{Determination of antifungal activity}

Antifungal effect of A. lakoocha fruits was determined by poisoned food technique (Grover et al., 1962, Mishra et al., 1992, Nene et al., 2002). Potato dextrose agar was used as a culture medium. For this $10 \%$ sample solution was taken with a sterilized pipette in a sterilized petri dish and then $15 \mathrm{ml}$ of medium was poured into the petri dish to mix well and allowed to solidify. Inoculation was done at the centre of each plate with 5 $\mathrm{mm}$ of mycelium block for each fungus. The mycelium block was prepared with the help of cork-borer from the growing area of a fiveday-old culture of the test fungi on potato dextrose agar. To get greater contact of the mycelium with the culture medium the blocks were placed at the centre of each petri dish in an inverted position. After 5 days of incubation, the diameters of fungal colonies were measured. The experiment was repeated 
three times. Nystatin $30 \mu \mathrm{g} /$ disc was used as positive control. Negative controls were made using paper discs treated with $20 \mu \mathrm{l}$ of the solvents.

\section{Results and Discussion}

The present study demonstrated that all the extracts of $A$. lakoocha fruits showed antibacterial activity (Table 1) and antifungal activity (Table 2) against reference microorganisms. Petroleum ether and chloroform exhibited antibacterial activity at the concentration of $0.20,0.40,0.60$, and $1.00 \mathrm{mg} / \mu \mathrm{l}$. But methanol extract showed antibacterial activity at the concentration of $0.10,0.20,0.40,0.60$, and $1.00 \mathrm{mg} / \mu \mathrm{l}$.

Distinct solvents reveal different activity against microorganisms. In our experiment, three different solvents were used which have different polarities. Among the three solvents, petroleum ether is non-polar, chloroform is more polar than petroleum ether and methanol is most polar than previous two solvents.

Petroleum ether extract of fruits of Artocarpus lakoocha Roxb showed the lowest activity compared to chloroform and methanol extracts. Among the three extracts, methanolic extract of the fruit exhibited strongest antimicrobial activity against the reference microorganisms which certainly point out that methanolic extract contains a higher concentration of active antimicrobial agents. Also, this could be due to the polarity nature to the active microbial compounds including alkaloids, carbohydrates, glycosides, saponin is present in these fruits.

Previous studies had also demonstrated that Artocarpus lakoocha Roxbis very rich in proteins and steroids (Dubey et al., 2015). The fruit extracts showed antibacterial activity with a zone of inhibition of 4 to 20 $\mathrm{mm}$. The methanolic fruit extract of Artocarpus lakoocha Roxb. paraded a broad- spectrum antibacterial activity with a zone of inhibition of 17 to $20 \mathrm{~mm}$. Different reports showed that methanolic extracts exhibited broader spectrum antimicrobial activity (Hossain et al.,2014, Jeong et al., 2009, Patrick et al., 2011). Our result indicated the similar result. On the other hand, chloroform extract exhibited a broad-spectrum antibacterial activity with a zone of inhibition of 17 to $20 \mathrm{~mm}$ against some bacterial species and petroleum ether extract showed comparatively narrow spectrum antibacterial activity with a zone of inhibition of 11 to 15 $\mathrm{mm}$ against reference bacterial species. The activity of the standard drug, Kanamycin was found higher than these fruit extract concentrations showing 24-30 $\mathrm{mm}$ in diameter against all the tested bacterial strains.

Moreover, the extracts of the fruit were active against the tested fungal species. Methanolic fruit extract had a very promising inhibitory effect on fungal strains compared to the reference antifungal drug nystatin same as antibacterial activity.

Comparisons of the three extracts it is clear that the methanolic fruit extract has significant activity, chloroform extract has moderate activity and petroleum ether extract has the least activity against Candida albicans and Candida krusei. From our experiment, it is clear that more polar solvents have significant antimicrobial activity than nonpolar solvents which have similarities with other reports (Das et al., 2012; Mwambete et al., 2009). It was reported that steroids are a major component that acts as an antifungal secondary metabolite (Onwuliri et al., 2005). As the fruits have steroids (Dubey et al., 2015) so these findings suggest that the antifungal effect of Artocarpus lakoocha extract is probably due to the individual or interactive effect of the secondary metabolites present in the extract. 
Table.1 Antibacterial activity of fruits of Artocarpus lakoocha Roxb

\begin{tabular}{|c|c|c|c|c|c|c|c|c|c|c|c|c|c|c|c|c|c|c|}
\hline \multirow[t]{3}{*}{ Microorganisms } & \multicolumn{17}{|c|}{ Different extracts of fruits of Artocarpus lakoocha Roxb (Zone of inhibition) } & \\
\hline & \multicolumn{6}{|c|}{ Petroleum ether $(\mathrm{mg} / \mu \mathrm{l})$} & \multicolumn{6}{|c|}{ Chloroform $(\mathrm{mg} / \mu \mathrm{l})$} & \multicolumn{5}{|c|}{ 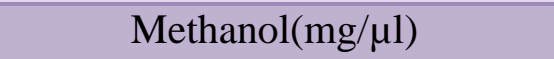 } & \\
\hline & 0.075 & 0.10 & 0.20 & 0.40 & 0.60 & 1.00 & 0.075 & 0.10 & 0.20 & 0.40 & 0.60 & 1.00 & 0.075 & 0.10 & 0.20 & 0.40 & 0.60 & 1.00 \\
\hline Escherichia coli & - & - & + & + & ++ & ++ & - & - & + & ++ & ++ & +++ & - & + & ++ & +++ & +++ & +++ \\
\hline Bacillus subtilis, & - & - & + & + & + & ++ & - & - & + & ++ & ++ & ++ & - & - & + & ++ & +++ & +++ \\
\hline $\begin{array}{l}\text { Staphylococcus } \\
\text { aureus, }\end{array}$ & - & - & - & + & + & + & - & - & + & + & ++ & ++ & - & + & ++ & +++ & +++ & +++ \\
\hline Salmonella typhi, & - & - & + & + & ++ & ++ & - & - & + & + & ++ & +++ & - & + & + & ++ & ++ & +++ \\
\hline Bacillus cereus, & - & - & + & + & + & + & - & - & + & ++ & ++ & ++ & - & + & ++ & +++ & +++ & +++ \\
\hline $\begin{array}{l}\text { Salmonella } \\
\text { paratyphi }\end{array}$ & - & - & + & + & ++ & ++ & - & - & + & + & ++ & +++ & - & + & + & ++ & ++ & +++ \\
\hline Positive control & & & & & & & & & & & & & & & & & & \\
\hline 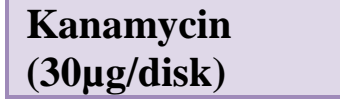 & & & +++ & & & & & & +++ & & & & & & +++ & & & \\
\hline
\end{tabular}

Table.2 Antifungal activity of fruits of Artocarpus lakoocha Roxb

\begin{tabular}{|c|c|c|c|c|c|c|c|c|c|c|c|c|c|c|c|c|c|c|}
\hline \multirow[t]{3}{*}{ Microorganisms } & \multicolumn{18}{|c|}{ Different extracts of fruits of Artocarpus lakoocha Roxb } \\
\hline & \multicolumn{6}{|c|}{ Petroleum ether $(\mathrm{mg} / \mu \mathrm{l})$} & \multicolumn{6}{|c|}{ Chloroform $(\mathrm{mg} / \mu \mathrm{l})$} & \multicolumn{6}{|c|}{$\operatorname{Methanol}(\mathrm{mg} / \mu \mathrm{l})$} \\
\hline & 0.075 & 0.10 & 0.20 & 0.40 & 0.60 & 1.00 & 0.075 & 0.10 & 0.20 & 0.40 & 0.60 & 1.00 & 0.075 & 0.10 & 0.20 & 0.40 & 0.60 & 1.00 \\
\hline Candida albicans & - & - & - & - & + & + & - & - & - & + & + & ++ & - & + & ++ & ++ & ++ & +++ \\
\hline Candida krusei & - & - & - & - & + & + & - & - & - & + & ++ & +++ & - & - & + & ++ & +++ & +++ \\
\hline Positive control & & & & & & & & & & & & & & & & & & \\
\hline
\end{tabular}

Nystatin

$+++\quad+++$

$+++$

(30 $\mathrm{gg} / \mathrm{disk})$

Experiments were done in triplicate. Diameter of zone of inhibition: $-<4 ;+=5-10 ;++=11-15 ;+++>16$. 
In conclusion, this study represents the preliminary report on the antimicrobial activity of the fruit extracts of Artocarpus lakoocha Roxb. against both the bacterial and fungal strains. The results suggest that Artocarpus lakoocha fruits are very promising as an antimicrobial agent. Further studies are recommended that will involve various parts of the plant from distinct areas and select different fractions of crude extracts and also purify the most active antimicrobial components.

\section{References}

Afolayan, A.J. Extracts from the shoots of Arctotis arctotoides inhibit the growth of bacteria and fungi. Pharmaceutical Biology. 2003; 41: 22-25.

Aliero, A.A., Afolayan, A.J. Antimicrobial activity of Solanum tomentosum. Afr. J. Biotechnol. 2006; 5: 369-372.

Calixto, J.B. Efficacy, safety, quality control, marketing and regulatory guidelines for herbal medicines (phytotherapeutic agents). Braz. J. Med. Biol. Res. 2000; 33:179-189.

Charoenlarp, P., Radomyos, P., Harinasuta, T. Treatment of taeniasis with PuagHaad: a crude extract of Artocarpus lakoocha wood. Se Asian J Trop Med. 1981; 12: 568-570.

Das, S.N., Patro, J.V and Dinda, S.C. Antimicrobial activity of Leucas clarkei. Bangladesh J. Pharmacol. 2012; 7: 135-139.

Dubey, K.B, Kiran, S., Tripathi, A.C., Koshy, $\mathrm{M}$ and Saraf, S.K. Artocarpus lakoocha Fruits: Phytochemical Investigation and Anti- Spermatogenic Potential. J. Nat. Prod. 2015; 5(7):5056.

Grover, R.K and Moore, J.D. Toximetric studies of fungicides against brown rot organisms, Sclerotia fructicola and $S$. laxa. Phytopathology. 1962; 52: 876880.

Hossain, M.S., Sayeed, M.A and Uddin, M.N. In-vitro antimicrobial activity of methanolic extract of Ficus racemosa Linn. Fruits. Journal of Scientific and Innovative Research. 2014; 3(4): 446449.

Jahan, S., Gosh, T., Begum, $M$ and Saha, B.K. Nutritional Profile of Some Tropical Fruits in Bangladesh: Especially Antioxidant Vitamins and Minerals, BJMS. 2011; 10, 2.

Jeong, M.R., Kim, H.Y and Cha, J.D. Antimicrobial Activity of Methanol Extract from Ficus carica Leaves Against Oral Bacteria. J Bacteriol Virol. 2009; 39(2): 97-102.

Khare, C.P. Indian Medicinal Herbs: An illustrated dictionary. Spring-erVerlag Berlin/Heidelberg, 2007; pp 66.

Likhitwitayawuid, K., Sritularak, B., Benchanak, K., Lipipun, V., Mathew, J., Schinazi R.F. Phenolics with antiviral activity from Millettia erythrocalyx and Artocarpus lakoocha. Nat. Prod. Res. 2005; 19(2): 177-182.

Mishra, M and Tiwari, S.N. Toxicity of Polyalthia longifolia against fungal pathogens of rice. Indian Phytopathology.1992; 45: 56-61.

Mwambete, K.D. The in vitro antimicrobial activity of fruit and leaf crude extracts of Momordica charantia: A Tanzania medicinal plant. Afr. J. Health Sci. 2009; 9: 34-39.

Navarro, V., Villarial, M.L., Rojas, $G$ and Lozoya, X. Antimicrobial evaluation of some plants used in Mexican traditional medicine for the treatment of infectious diseases. $J$ Ethnopharmacol. 1996; 53: 143-147.

Nene, Y and Thapilyal, L. Poisoned food technique of fungicides in plant 
disease control, 3rd ed. Oxford and IBH Publishing Company: New Delhi;2002.

Onwuliri, F.C and Wonang, D.L. Studies on the combined antibacterial action of Ginger (Zingiber officinale L) and Garlic (Allium sativum L.) on some bacteria. Nigerian journal of botany. 2005; 18: 224-28.

Pandey, A and Bhatnagar, S.P. Antioxidant and Phenolic Content of the Bark of Artocarpus lakoocha. The Pharma Review. 2009; 1: 23-28.

Patrick, V.K., Ango, Y., Fotso, G.W., Kapche, G.D., Dzoyem, J.P., Wouking, A.G.et al., Antimicrobial activities of the methanol extract and compounds from Artocarpus communis (Moraceae). BMC Complem Altern M. 2011; 11: 42.

Perry, L.M. Medicinal Plants of East and Southeast Asia: Attributed Properties and Uses, MIT Press, Cambridge: 1980;149-50.

Piyush, G and Ramesh, P. Artocarpus lakoocha Roxb: An overview. EJCAM. 2014; 1(1):10-14.

Prashant, K.R., Dolly, J., Singh, K.R., Gupta, K.R., Watal, G. Glycemic properties of Trichosanthes dioica leaves.
Pharmaceutical Biology. 2008; 46:894-899.

Puntumchai, A., Kittakoop, P., Rajviroongit, S., Vimuttipong, S., Likhitwitayawuid, K., Thebtaranonth, Y., Lakoochins A and $\mathrm{B}$, new antimycobacterial stilbene derivatives from Artocarpus lakoocha. J. Nat. Prod. 2004; 67(3): 485-486.

Salguero. C.P. A Thai Herbal Traditional Recipes for Health and Harmony. Findhorn Press, Scotland: 2003; 119.

Sein, T.T., Spurio, R., Cecchini, C and Cresci, A. Screening for microbial strains degrading glass fiber acrylic composite filters. Int. Biodeterior. Biodegradation. 2009; 63(7): 901-905.

Swain, S.R., Sinha, B.N and Murthy, P.N. Antiinflammatory, diuretic and antimicrobial activity of Rungia pectinata Linn. and Rungia repens Nees. Indian J Pharm Sci. 2008; 70: 679-683.

Tomar, A., Srivastava, A and Dubey, K. Need of Conservation Approach of Underutilized Fruits: A Potential of Local Resource, Uttar Pradesh Biodiversity Board, International Day for Biological Diversity-Biodiversity for Sustainable Development. 2015. [http://www.upsbdb.org/pdf/Souvenir 2015/ch-22.pdf]

\section{How to cite this article:}

Srabonti Saha. 2019. In vitro Antimicrobial Activity of Bangladeshi Artocarpus lakoocha Roxb Fruits. Int.J.Curr.Microbiol.App.Sci. 8(02): 438-444.

doi: https://doi.org/10.20546/ijcmas.2019.802.049 